\title{
Green Criminology and (Constructions of) Environmental Crime and Harm: A Review Essay
}

\author{
Hanneke Mol ${ }^{1}$
}

Published online: 10 December 2015

(C) The Author(s) 2015. This article is published with open access at Springerlink.com

Brisman and South: Green Cultural Criminology: Constructions of Environmental Harm, Consumerism, and Resistance to Ecocide. Routledge, Oxford and New York, 2014, 162 pp

Brisman, South, and White: Environmental Crime and Social Conflict: Contemporary and emerging issues. Ashgate, Farnham and Burlington, 2015, 328 pp

That green criminology is a vibrant area of scholarship and continues to extend, deepen, and refine its analysis of contemporary and emerging environmental issues, is once more demonstrated in two recent contributions to the field: Green Cultural Criminology: Constructions of Environmental Harm, Consumerism, and Resistance to Ecocide, by Avi Brisman and Nigel South, and Environmental Crime and Social Conflict: Contemporary and emerging issue, an edited collection by the latter two scholars and Rob White. The first book integrates explicit attention for the cultural into green criminological analysis and as such adds greatly to the analytical and theoretical depth of the field. With an opening passage that draws attention to our current day climate, energy, and environmental crises through the storylines of animation films Monsters Inc. and Monsters University, Brisman and South immediately pull the reader into the heart of the argument advanced in Green Cultural Criminology: for a thorough understanding of the nature and persistence of environmental harm and crime in late modern consumerist society, it is necessary to connect the dots between contemporary political, economic, and cultural forces and processes; representations of environment and 'nature'; and constructions of environmental crime and harm. In turn, the edited collection Environmental Crime and Social Conflict bundles a variety of works that from diverse geographical, analytical, theoretical, and substantive foci interrogate the links between environment and conflict. The editors thereby set themselves three aims: (1) provide a baseline resource for criminologists

Hanneke Mol

hanneke.mol@northumbria.ac.uk

1 Northumbria University, Newcastle upon Tyne, UK 
concerned with the multiple connections between environments and conflict; (2) highlight — and add to - the international compass of green criminological analysis, and; (3) work towards a typology of environment-conflict relationships. Hence, the book wonderfully reveals the complexity and multi-dimensionality of the dynamics and realities underpinning this area of research and substantive concern.

The books connect and complement each other in various ways. One example that springs to mind and that merits mention here, is the social conflict linked to the commodification of nature - and the prospects of exacerbated conflict around such matters into the future. Connecting the dynamics and impacts of the commodification of nature-a theme comprehensively dealt with in Green Cultural Criminology - to the edited collection's focus on social and environmental conflict, reveals that it is not only the actual decline (i.e. depletion) of natural resources that contributes to conflict, but that conflict can just as much be triggered by the exclusionary dynamics linked to the transformation of public goods into privatized commodities and the consequent decline of publicly accessible or available natural goods (e.g. water) for those that lack the means to purchase what has now been turned into a consumer product. Let us look more closely at the approach taken in Green Cultural Criminology first.

In their co-authored book, Brisman and South set out to direct much needed attention to "the cultural significance of (the) environment, environmental crime, and environmental harm" (p. 118), encouraging green criminologists to engage the cultural dimension of green issues by focusing on: (1) corporate, political, and popular constructions and mediated representations of environment, environmental crime, and environmental harm; (2) the commodification of nature and the cultural construction of needs that feed the expansionary drive of capitalism; and (3) resistance to environmental harm and demands for the transformation of 'business as usual' and everyday processes and relations that are destroying the environment. The principal goal of Green Cultural Criminology, as the authors put it, is not "to identify weaknesses in previous approaches or to promote a particular solution to an environmental problem or set of environmental problems, but to examine existing overlapping research and to stimulate further investigation" (p. 7). The book does this particularly well and is definitely a source of inspiration for those intend on integrating cultural criminology's attention for the intersection of culture, crime, and justice into the analysis of green crimes and harms affecting nonhuman species, humans, ecosystems, and the environment at large.

Brisman and South make a compelling case that the cross-fertilization of these two areas of research and scholarship forms not only a necessary addition to existing green criminological work (an argument set up in an introductory way in chapter 1) but that this endeavour should equally appeal to cultural criminologists. In fact, the latter, according to Brisman and South, in their focus on the contestation of space in a way already "do" green criminology (after providing an overview of cultural criminology in chapter 2 , this argument is elaborated in chapter 3). Chapter 4 addresses constructions of environmental harm in the news media, documentaries, fiction and science-fiction. Chapter 5 reflects on the dynamics and consequences of the commodification of nature, the cultural construction of needs, and the appeal, limits, and mechanisms underpinning 'green' consumption. Applied to the case of bottled water, chapter 6 subsequently gives a thought-provoking account of late modern consumer culture's way of "creating the illusion of need and utility where none really exists (or, at least, not at the inflated price charged)" (p. 83), and how this comes to the detriment of nature and to those that cannot afford to purchase what was once a freely available, public good. Chapter 7 then addresses the playful, festive, theatrical, and carnivalesque forms of resistance that "rather than existing just in opposition to 
something" (p. 95), enact and embody the social and economic change, eco-philosophical principles, non-commercial values and community dynamics sought after by those involved in these forms of protest.

All in all, Brisman and South's book draws attention to the many disconnects that characterize contemporary forms of social and economic organization: between production and consumption; in the ways we (human beings) relate to and interact with nature, our environments, and fellow human beings (whether distant or next door); and how such disconnects become yet further exacerbated and entrenched with late modern consumer culture. The crimes and harms bound up with these disconnects are highlighted, as is the green criminological relevance of the playful, performative, and constructive forms of resistance that seek to reverse or repair these disconnects. Perhaps the only thing that is missing from the future research directions suggested in the concluding chapter is the need to also attend to the specific way(s) in which the intersection of environment, crime, justice, and culture plays out in and towards the Global South. Amongst other things, this would for instance include interrogating the colonial imagery that frequently tends to be mobilized to facilitate and legitimate the exploitation of the human and nonhuman populations and environments in distant regions of the 'South'. Developments are well under way to make green criminology more global in its reach and sensitivity; a viable green cultural criminology, too, must aspire and keep working to this aim. It must be said that, to some extent, elements of this are taken up in various chapters of the edited collection, most notably in chapters $4,7,9$, and 10 . Although more work needs to be done, we do see here another dimension in which the books in a way quite nicely complement each other, but also, how one of the books-in this case Environmental Crime and Social Conflictcontains important leads, and exhibits the potential, to draw stronger connections between the two projects. Let us turn to the edited collection in more detail.

In terms of the book's structure, the editors have organized the chapters into four sections that mirror the typology of environment-conflict relationships set out in the introductory chapter, acknowledging fluidity and overlap. The first section ('Conflict over natural resource possession') consists of four chapters. In the first (chapter 2), Tanya Wyatt explores the correlations between illegal logging and inter-human conflict. Overlaying maps of documented conflicts with areas known to be affected by illegal logging, an overlap presents itself in 16 countries. Although it can be hard to pin down if logging thereby forms the reason for or funding source of conflict, Wyatt stresses that consequent human and environmental suffering is substantial either way and that in order to detect, halt, or reverse situations where illegal logging and inter-human conflict are connected, a thorough understanding of the nature of this connection is crucial. Wyatt does not so much provide definitive answers as give an important impetus to, and basis for, further research into this area.

In chapter 3, Richard Milburn addresses the pressures exerted on the environment as a consequence of armed conflict in the Democratic Republic of Congo. Organized around a focus on ivory, charcoal, and timber, Milburn seeks to direct more specific attention to the living environment as a casualty and funding source of conflict, stating that this reality is still relatively understudied compared to the links between conflict and precious metals and minerals. The chapter's strength lies in the insight it offers into the cross-border complexities of the situation in the DRC, the variety of actors involved, and how environmentconflict relations in the DRC are intricately interwoven with conflict and 'post-conflict' dynamics in the wider region. Milburn moreover raises the prospect of the environment as a peacebuilding route, although this is somewhat undermined when later contemplating the 
reintegration of former rebels into army units charged with conservation, if we consider the risks this carries in terms of sliding into a militarization of conservation.

Attention then shifts to Colombia, where, as David Rodríguez Goyes describes in chapter 4, between 1 January 1958 and 31 December 2012 conflict over land access, use, and ownership -in the context of armed conflict, large-scale mining, agroindustrial operations and other mega-projects-has resulted in 220,000 deaths and 5.7 million internally displaced persons. Rodríguez Goyes rightly insists on the crucial need to hear the voices of those who suffer most from armed conflict and neoliberal assault. Attending to the testimonies and perspectives voiced during four citizen participation forums organized in the framework of ongoing peace negotiations between Colombia's government and the FARC, the chapter demonstrates that a stable, enduring, and inclusionary peace agreement crucially depends on tackling profound inequalities in land access and ownership as well as the historical disregard for rural communities' relation to and culturally specific uses of the land.

In chapter 5, Ragnhild Sollund's analysis of human-predator conflicts in Norway presents a wholly different type of conflict and shift in focus regarding the subject who suffers as a result of conflict. The chapter gives a strong and tragic account of the lack of intrinsic value accorded to the lives of wolves, lynx, bear, and wolverines in the clash with human interests. Scrutinizing practices of theriocide - a concept that counters the prevalent use of anthropocentric and speciesist terminology when it comes to the wilful killing of an animal, and the immense pain and suffering thereby inflicted-Sollund demonstrates how Norwegian predator policy and court verdicts do not so much problematize the taking of life as such as the 'irregularities' under which these animals are killed, exposing the anthropocentrism and speciesism that imbue the normative framework in which decisions over life and death are made.

Section 2 ('Conflict over declining resources') consists of two chapters. In chapter 6, Bram Ebus and Karlijn Kuijpers scrutinize the adverse impacts and human rights violations that accompany the convergence of state and corporate interests and powers in the context of goldmining in Colombia and hydroelectric dams in Brazil. The authors expose the voluntary practices and rhetoric of Corporate Social Responsibility for what these truly facilitate and deflect: massive waves of forced displacement, the elimination of local opposition, and the destruction of human and nonhuman lives. That this is infused by a pervasive denial stands beyond doubt; whether, as the authors argue, the involved actors require the resort to techniques of neutralization is less evident. Nonetheless, the statecorporate (and in Colombia, the state-corporate-paramilitary) interface that is driving and perpetuating social and environmental harm and crime in these contexts is powerfully laid bare.

Chapter 7, by Victoria Collins, addresses the aetiology of piracy in Somalia. Collins points out that the environmental harm and degradation generated by illegal fishing, toxic waste dumping, and periods of extreme drought form a crucial dimension of the structural and economic conditions that underpin the criminogenic context driving piracy. Collins moreover points out that practices of piracy are imbued with politics, in that they developed in response to the assaults and economic hardship experienced at the hands of foreign trawlers engaged in illegal fishing off the coast of Somalia and the dumping of waste in the waters that sustained the livelihoods of local coastal populations. But rather than targeting these root causes that continue to produce massive social and environmental harm, billions of dollars are pumped into the war on the 'maritime terrorism' of Somali pirates.

In the first of three chapters that make up section 3 ('Conflict that destroys environments'), Aaron Fichtelberg problematizes the lack of legal protection of the environment in 
modern resource wars, wherein natural resources are deeply integrated with the very conduct of war rather than a mere motive for war or reward for victory. As pointed out, neither of the two areas of international law of relevance here-humanitarian law and environmental law-were designed to aptly deal with environmental harm and degradation generated in the course of contemporary warfare and armed conflict, leaving the environment utterly exposed to conflict-related destruction. While humanitarian law has long sought to humanize warfare, this protection is yet to be meaningfully extended to the environment; as a victim in itself, and as a medium of victimization. Fichtelberg thus proposes "the criminal exploitation of natural resources in wartime" to be included as a new crime of war, and to extend criminal liability to individuals and organizations that trade in natural goods obtained in the course of armed conflict.

In chapter 9 M.L.R. Smith and Jasper Humphreys analyse the 'rhinofication' of national security in South Africa. The dynamics of a militarized counter-poaching strategy, and the historical, social, and political background against which these dynamics must be understood, are reflected on. As the authors suggest, rather than an effective means to protect the lives of rhinos there is every reason to perceive the war on poaching as a strategy that serves little more than the interests of a minority elite, thus reproducing white privilege rather than taking on the complex task of tackling the issue of poaching through a simultaneous focus on the social and economic inequality experienced by South Africa's rural, and by and large black, poor.

Tyler Wall and Bill McClanahan, too, in chapter 10, offer a critique of the war on poaching, or, as it is aptly put, the weaponisation of conservation. Interrogating and exposing the (neo)colonialist premises and practices of 'fortress conservation', the authors challenge Eurocentric constructions of poaching, (pristine) nature, and conservation, demonstrating that these inherently political terms facilitate and legitimate not only the eviction and exclusion of local peoples from the lands they have historically lived from, on, and with, but also the hunting of local subjects, who are recast as threats to wildlife and social order. Lest it is thought that this stems from a concern with the intrinsic worth and physical integrity of 'protected' species, Wall and McClanahan are clear that the war on poachers "is not merely against poachers [but] simultaneously for accumulation" (p. 236, emphasis in original). In what bears similarity to Sollund's observation in chapter 5 about the protection of cattle against nonhuman predators-only to be killed for human consumption later - here, ancestral lands and socionatural spaces are converted into enclosed sites of capitalist accumulation where animals are legitimately chased and gunned down by wealthy (overwhelmingly white) foreigners, or gazed at by affluent (again, overwhelmingly white) tourists.

Finally, part 4 ('Conflict over Natural Resources Extraction Processes'), consists of 2 chapters. Kerry Carrington, Russell Hogg and Alison McIntosh discuss the disruptive effects of post-industrial mining regimes in Australia-in particular how this pertains to the shift to an all but exclusively non-resident workforce. The sudden influx of a young and predominantly male labour force experienced in mining towns, tends to dislocate local community dynamics and bring about increased levels of violence and social disorder. The chapter gives a cogent account of the social consequences of the prioritization of the economic interests of the mining sector at the expense of the well-being of the Australian public by successive Australian governments.

In chapter 12, resonating with Brisman and South's Green Cultural Criminology, Nels Paulson, Kim Zagorski and D. Chris Ferguson shed light on the dominant frames used in media constructions of the nature of the 2010 Gulf of Mexico oil spill in terms of the oil spill's origins, impacts, associated risk, and perceived solutions. The authors point to the 
all but complete absence of the voices of those that are most vulnerable to the environmental harms and risks surrounding oil spills. On a more positive note, the chapter concludes by noting the potential for "re-framing environmental harm, conflict, and vulnerability in the age of globalisation" (p. 280), and the role green criminology ought to play in such endeavours.

Lastly, building on and pushing further (and hence coming back full circle to) the project of green cultural criminology, Avi Brisman analyses the representation of environment and conflict in literary and cinematic fiction, laying bare the problematic messages that such outlets communicate in relation to the causes, impacts, and implications of human-induced environmental degradation. Brisman likewise posits the need to not only analyse fictional (as well as nonfiction) representations and narratives of environmental harm and conflict, but also create alternative stories that are more constructive towards the aim of halting, and possibly revert, the environmental degradation through which we are fast destroying our planet and the human and nonhuman life dependent on it.

Taken together, the chapters of the edited book demonstrate how the environment can be a casualty of conflict (i.e. suffer the consequences of conflict), be utilized or abused as an instrument of conflict (when conflict is waged through or by means of the environment), or form the cause of conflict (as a result of diverging uses and meanings ascribed to a particular environment), at various points giving expression (sometimes implicitly, sometimes more explicit) to the cultural content and significance of environment-conflict links. The editors' typology thereby constitutes a novel attempt at bringing analytical clarity into the complex and multiple links between environment and conflict, but is also a necessity to hold a set of widely divergent chapters together. On a more critical note, the organization of the chapters into the four categories of the editors' typology felt slightly forced at times and restrains the full potential of two chapters in particular. That is, both Wall and McClanahan's and Sollund's chapter suggest a refinement of the environmentconflict typology that appears to be missed by the editors. Would conflict over 'conservation' and the 'protection' of (a select number of) environments and/or species-and the (shifting) boundaries thus drawn between what is and what is not worthy of being conserved or protected, who does and who does not have the right to enjoy (or abuse) 'nature'-not merit to be analysed as a category in itself? Especially the choice of the editors to place Wall and McClanahan's chapter in a section on environmental destruction seems to be somewhat at odds with what precisely this chapter has to contribute to a tendency within green criminology to frame environmental harm and crime predominantly in terms of a rigid capital-nature antagonism that overlooks the ways that capital may shape nature rather than destroying it at once, at all, or in its entirety. That way the typology would arguably resonate stronger with the project of green cultural criminology, too. Still, the impetus that Brisman, South and White give to exploring environmentconflict relationships is to be applauded and carried forward.

Open Access This article is distributed under the terms of the Creative Commons Attribution 4.0 International License (http://creativecommons.org/licenses/by/4.0/), which permits unrestricted use, distribution, and reproduction in any medium, provided you give appropriate credit to the original author(s) and the source, provide a link to the Creative Commons license, and indicate if changes were made. 